\title{
Putrescine Accumulation is Associated with Growth Inhibition in Suspension- Cultured Rice Cells under Potassium Deficiency
}

\author{
Hung-I Sung, Li-Fei Liu and Ching Huei Kao
}

Department of Agronomy, National Taiwan University, Taipei, Taiwan, Republic of China

\begin{abstract}
The effects of potassium deficiency on the growth and the polyamine levels of suspension-cultured rice cells were investigated. Our results indicate that putrescine accumulation is a factor, among others, causing growth inhibition of suspension-cultured rice cells under potassium deficiency.
\end{abstract}

Key words: Cell growth - Oryza sativa - Potassium deficiency - Putrescine - Spermidine Spermine.

Availability of potassium is known to have a large impact on plant growth. It has been shown that potassium deficiency induces an accumulation of polyamines and especially, accumulation of a diamine, Put, in several plant species (Basso and Smith 1974, Coleman and Richards 1956, Klein et al. 1979, Klinguer et al. 1986, Murty et al. 1971, Richards and Coleman 1952, Smith 1963, 1969, 1979, Steward et al. 1960, Tachimoto et al. 1992, Takahashi and Yoshida 1960, Young and Galston 1984). In spite of extensive study, the physiological role of Put accumulation induced by potassium deificiency remains unanswered. It has been suggested that accumultaiton of Put might play a role in the replacement of potassium as an organic cation in potassium deficient plants (Coleman and Richards 1956, Murty et al. 1971). However, Richards and Coleman (1952) suggested that potassium-deficient symptoms in barley are a consequence of Put buildup, since the symptoms characteristic of potassium deficiency were produced in barley plants fed Put. Since Put is applied to intact plants under unaseptic conditions, the possibility that the decomposition of Put may cause toxic effects on the plants can not be excluded. Recently, Tachimoto et al. (1992) investigated the role of Put in potassium-deficient Lemna plant using aseptic culture and reached the conclusion that accumulation of Put might function in maintaining an ionic balance in this plant.

The present investigation was designed to examine the

Abbreviations: D-Arg, D-arginine; MO, a-methylornithine; Put, putrescine; SCV, settled cell volume; Spd, spermidine; Spm, spermine. role of Put in suspension-cultured rice cells under potassium deficiency. We present data showing that Put accumulation is associated with growth inhibition in suspension-cultured rice cells.

Rice (Oryza sativa cv. Tainan 5) suspension cultures were initiated from immature embryo derived calli (Yu et al. 1991) and subsequently maintained at $25^{\circ} \mathrm{C}$ by weekly transfers to fresh liquid medium of Murashige and Skoog (1962) supplemented with $3 \%$ sucrose and $5 \mu \mathrm{M} 2,4-\mathrm{D}$.

Suspension-culutred cells were collected by filtration through a 400 -mesh nylon sieve, and blot-dried on paper towels. The collected cells were quick-frozen in liquid nitrogen and stored at $-70^{\circ} \mathrm{C}$ until use.

The growth of rice cells was measured by settled cell volume (SCV). For polyamine determination, the collected cells were homogenized in $5 \mathrm{ml}$ of $5 \%$ perchloric acid. Polyamine contents were determined using high performance liquid chromatography after benzoylation as described previously (Chen and Kao 1991).

For all measurements, each treatment was repeated four times. All experiments described here were repeated three times. Similar results and identical trends obtained each time. The data reported here are from a single experiment.

Potassium deficiency markedly inhibited the growth of suspension-cultured rice cells (Fig. 1). The growth of rice cells with sufficient supply of potassium increased linearly with increasing duration of culture. However, only slight growth was observed in rice cells under potassium deficiency.

To characterize the role of polyamines in the growth 


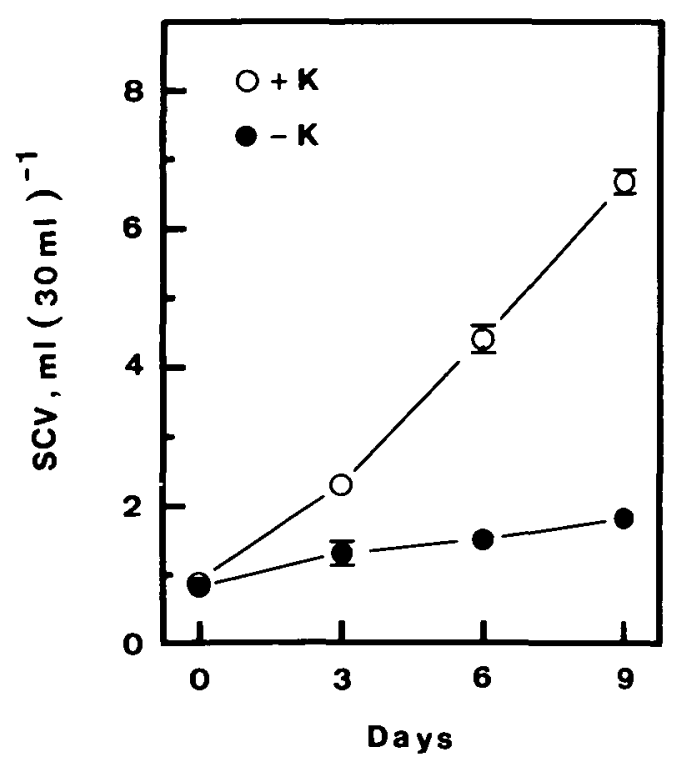

Fig. 1 Changes in the growth of rice cells cultured with sufficient potassium $(+K)$ and under potassium deficiency $(-K)$.

of rice cells under potassium deficiency, we determined the levels of polyamines in the cells cultured in the presence and absence of potassium. The chromatographic analysis indicated the presence of Put, Spd and Spm in suspensioncultured rice cells. However, cadverine and diaminopropane were not observed in rice cells. The level of Put in the control cells (supplied with sufficient potassium) decreased at day 3 but increased between days 6 and 9 (Fig. 2). Potassium-deficient rice cells had much higher level of Put than the control cells as reported in other plant species (Smith 1984). The levels of Spd and Spm in control cells increased at day 3 and subsequently declined (Fig. 2). Potassium deficiency resulted in lower levels of Spd and Spm than the control cells.

If the lower levels of Spd and Spm are responsible for the growth inhibition in rice cells under potassium deficiency, then potassium-deficient cells are expected to recover the growth by the addition of Spd and Spm. However, no such recovery was observed (data not shown).

Tachimoto et al. (1992) demonstrated that Put added to the culture medium induced the recovery of the growth of Lemna plnats under potassium deficiency to some extent, although the level of Put markedly increased. They concluded that Put acted as an organic cation compensated for the deficiency in potassium ion. When Put up to $10 \mathrm{mM}$ was added to the culture medium of rice cells under potassium deficiency, no recovery of growth was observed (data not shown). Thus, our results are not consistent with those of Tachimoto et al. (1992). It seems most likely that Put is a factor causing growth inhibition in rice cells under potassium deficiency. If this suggestion is correct, then Put is ex-

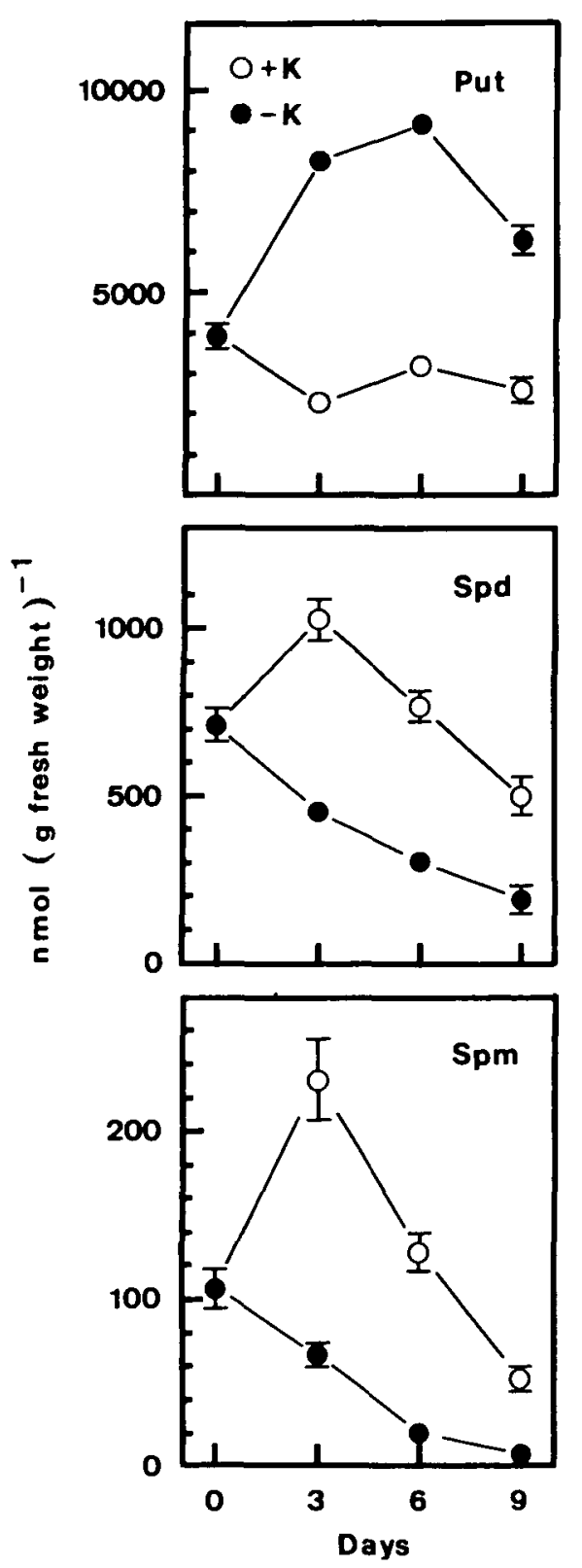

Fig. 2 Changes in levels of polyamines in rice cells cultured with sufficient potassium $(+K)$ and under potassium deficiency $(-K)$.

pected to inhibit the growth in control rice cells. Addition of Put $(10 \mathrm{mM})$ to control rice cells resulted in about $20 \%$ reduction in cell growth (data not shown). Our results are in contrast to the general notion that, in many systems representing plants, microorganism and animals, polyamine treatment has resulted in growth promotion (Smith 1990).

Inhibitors of polyamine biosynthesis have been widely used to change the levels of endogenous polyamines in plant tissues. In order to elucidate further the role of Put accumulation in growth inhibition of rice cells under potas- 


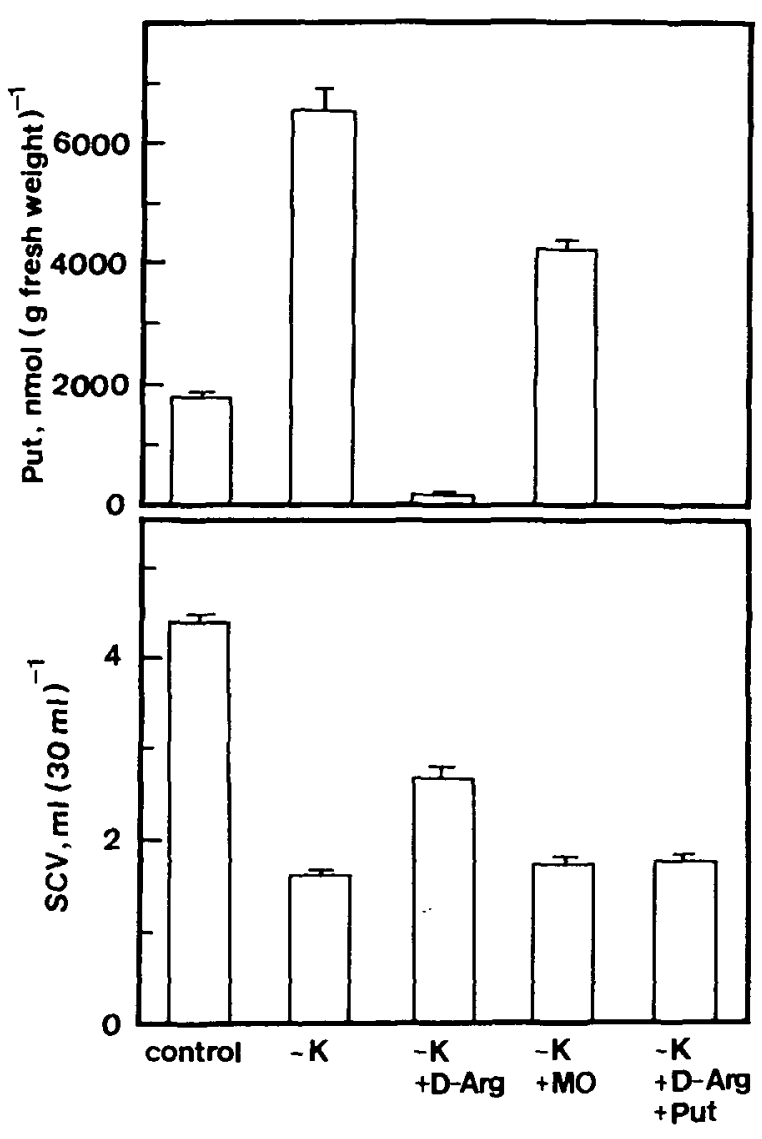

Treatment

Fig. 3 Effect of D-arginine (D-Arg) and $\alpha$-methylornithine (MO) on the level of putrescine (Put) in and the growth of rice cells under potassium deficiency. The concentration of D-Arg and MO was $5 \mathrm{mM}$. Put and the growth of rice were determined after 9 days of treatment. SCV at the start of the experiment was $1 \mathrm{ml}$ $(30 \mathrm{ml})^{-1}$.

sium deiciency, we tested the effects of inhibitors of Put biosynthesis on the level of Put in and the growth of rice cells under potassium deficiency (Fig. 3). Both D-Arg and MO decreased the levels of Put induced by potassium deficiency (Fig. 3). Although we did not meassure the activities of arginine decarboxylase and ornithine decarboxylase, enzymes responsible for the biosynthesis of Put (Smith 1990), our results suggest, though indirectly, that potassium deficiency may affect the biosynthesis of Put.

D-Arg treatment resulted in a recovery of growth in rice cells under potassium deficiency, but MO had no effect on growth recovery (Fig. 3). Although MO significantly reduced the accumulation of Put induced by potassium deficiency, MO-treated potassium-deficient rice cells still had two times higher level of Put than the control cells (Fig. 3). This would explain why MO is unable to recover the growth inhibited under potassium deficiency. Our results suggest that Put accumulation is a factor causing growth inhibition of rice cells under potassium deficiency. This conclusion is further supported by the observation that growth recovery in potassium-deficient rice cells by $\mathrm{D}$-Arg was reversed by the addition of Put (Fig. 3). Since D-Arg treatment resulted in only a partial recovery of growth in rice cells under potassium dificiency, other factors induced by potassium deficiency that are responsible for growth inhibition can not be ruled out.

Our unpublished data also demonstrated that D-Arg but not MO inhibited the growth of control (potassiumsufficient) rice cells, though both inhibitors decreased the levels of Put. In view of these findings together with the fact that exogenous Put inhibited the growth of control cells, we believe that Put is unlikely to be a groth factor of the rice cells. On the contrary, Put in excess of the level that normally found in rice cells would be a factor inhibiting growth of rice cells.

Under unaseptic condition, it is difficult to analyze the effect of Put supplied exogenously to intact plants, since Put is easily decomposed especially under aerobic condition. Since suspension-cultured rice cells were grown under aseptic system, the results that polyamines inhibited growth of the control cells as reported in this communication are unlikely due to the decomposition products of Put. Thus, we conclude that Put accumulation is likely to be a factor, among others, responsible for growth inhibition in suspension-cultured rice cells under potassium deficiency.

This work was supported financially by the National Science Council of the Republic of China (NSC 83-0409-B-002-034) to C.H.K.

\section{References}

Basso, L.C. and Smith, T.A. (1974) Effect of mineral deficiency on amine formation in higher plants. Phytochemistry 13: 875883.

Chen, C.T. and Kao, C.H. (1991) Senescence of rice leaves XXX. Levels of endogenous polyamines and dark-induced senescence of rice leaves. Plant Cell Physiol. 32: 935-941.

Coleman, R.G. and Richards, F.J. (1956) Physiological studies in plant nutrition. XVIII. Some aspects of nitrogen metabolism in barley and other plants in relation to potassium deficiency. Ann. Bot. 20: 393-409.

Klein, H., Priebe, A. and Jager, H.-J. (1979) Putrescine and spermidine in peas: effects of nitorgen source and potassium supply. Physiol. Plant. 45: 497-499.

Klinguer, S., Martin-Tanguy, J. and Martin, C. (1986) K-Nutrition, growth, bud formation, and amine and hydroxycinnamicacid amide contents in leaf explants of Nicotiana tabacum cultivar Xanthi n. c. cultivated in vitro. Plant Physiol. 82: 561565. 
Murashige, T. and Skoog, F. (1962) A revised medium for rapid growth and bio-assays with tobacco tissue cultures. Physiol. Plant. 15: 473-497.

Murty, K.S., Smith, T.A. and Rould, C. (1971) The relation between the putrescine content and potassium status of black currant leaves. Ann. Bot. 356: 687-695.

Richards, F.J. and Coleman, R.G. (1952) Occurrence of putrescine in potassium deficient barley. Nature 170: 460 .

Smith, T.A. (1963) L-Arginine carboxy-lase of higher plants and its relation to potassium nutrition. Phytochemistry 2: 241-252.

Smith, T.A. (1969) Agmatine iminohydrolase in maize. Phytochemistry 2: 241-252.

Smith, T.A. (1979) Arginine decarboxylase of oat seedlings. Phytochemistry 18: 1447-1452.

Smith, T.A. (1984) Putrescine and inorganic ions. Adv. Phytochem. 18: 7-54.

Smith, T.A. (1990) Plant polyamines-metabolism and function. In Polyamines and Ethylene: Biochemistry, Physiology, and In- teractions. Edited by Flores, H.E., Arteca, R.N. and Shannon, J.C. pp. 1-23. American Society of Plant Physiologists, Maryland.

Steward, F.C., Hulme, A.C., Freiberg, S.R., Hegarty, M.P., Pollard, J.K., Rabson, R. and Barr, B.A. (1960) Physiological investigations on the banana plant. Ann. Bot. 24: 83-116.

Tachimoto, M., Fukutomi, M., Matsushiro, H., Kobayashi, M. and Takahashi, E. (1992) Role of putrescine in Lemna plants under potassium deficiency. Soil Sci. Plant Nutr. 38: 307-313.

Takahashi, T. and Yoshida, D. (1960) Relationship between the accumulation of putrescine and the nutrition of tobacco plant. J. Soil. Sci. Manure 31: 39-41.

Young, N.D. and Galston, A.W. (1984) Physiological control of arginine decarboxylase activity in $\mathrm{K}$-deficient oat shoots. Plant Physiol. 76: 331-335.

Yu, S.-M., Kuo, Y.-H., Sheu, G., Sheu, T.-J. and Liu, L.-F. (1991) Metabolic derepression in suspension-cultured cells of rice. J. Biol. Chem. 266: 21131-21137.

(Received September 27, 1993; Accepted November 20, 1993) 